
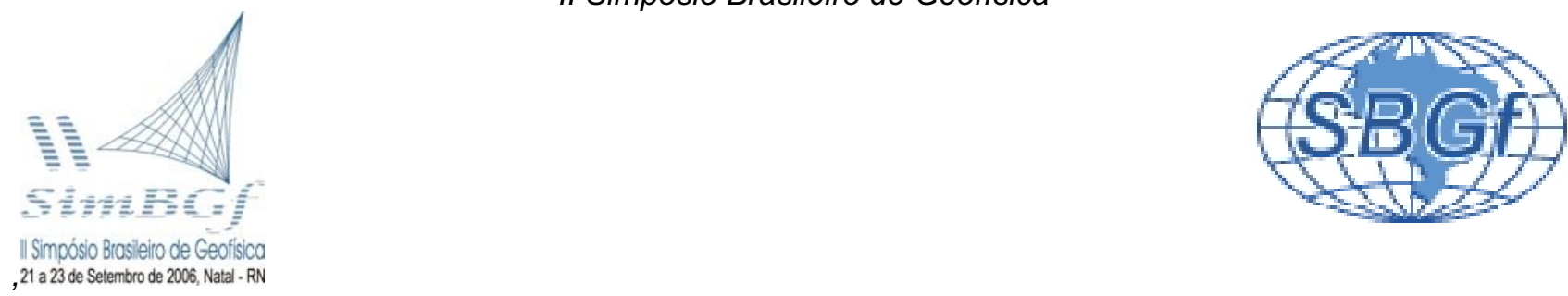

\title{
Hydraulic Fracture Mapping From Treatment Well. Channelized Reservoirs Development Optimization In Mexico
}

Sergio Berumen, Heron Gachuz, Juan Manuel Rodriguez, Pemex, Exploracion y Produccion, Mexico

Thierry Bovier Lapierre*, Createch Industrie, France.

Pénéloppe Kaiser, Magnitude, France

Copyright 2006, SBGf-Sociedade Brasileira de Geofísica

Este texto foi preparado para a apresentação no Il Simpósio de Geofísica da Sociedade Brasileira de Geofísica, Natal/RN, 21-23 de setembro de 2006. Seu conteúdo foi revisado pela Comissão Tecno-científica do II SR-SBGf mas não necessariamente representa a opinião da SBGf ou de seus associados. É proibida a reprodução total ou parcial deste material para propósitos comerciais sem prévia autorizaçãoda SBGf.

\begin{abstract}
The fracture stimulation becoming of prime interest for waterflooding and Enhanced Oil Recovery (EOR), the orientation of the fractures is a key factor for the selection of optimum well locations. The microseismic monitoring of hydraulic fracturing treatment appears then as an helpful tool to map fractures. This paper presents the results obtained by PEMEX in channelized Chicontepec reservoirs (Mexico), where extensive fracturing jobs are largely carried out to stimulate the oil recovery of the turbidites reservoir complexes. The specificity of the presented monitoring surveys stands in the deployment of tools in the treatment well itself. The microseismicity recorded yields to provide consistent orientation of fractures. These results confirm the great potential of this unique approach, as it leads PEMEX to review the stimulation scheme for a cost-effective reservoir stimulation.
\end{abstract}

\section{Introduction}

"Since hydraulic fracture well stimulation was introduced in the early 1950's, technology has increased tremendously. Frac job costs in certain situation may range upwards to $100 \%$ of well drilling cost" (Allen,T.O. and Roberts A.P.). The fracture stimulation is now of prime interest for waterflooding and EOR, and the selection of optimum well locations depends on orientation of propped fracture. Indeed, poor sweep efficiency occurs when long fractures channel the injected fluid towards producers (Figure 1). It is no longer necessary to prove that the microseismic monitoring of hydraulic fracturing treatment can be used for fracture mapping. Previous studies, Wolhart, Berumen et al, have shown that detection of microseismic events from an observation well is strongly controlled by the distance and rock mechanical properties between wells, and that field application have some serious limitations. Therefore, in numerous cases the only solution is to deploy the seismic tools in the treatment well itself. This apparent disadvantage provides, in fact, a unique way to monitor fracturing process from the "inside" (fluid and hammer pulse) and the "outside" (rock and shear slip events). In addition, with this kind of design the major monitoring parameters and the sensitivity remain the same from well to well. The monitoring is, of course, restricted to the fracture closure time after pumping shut down. However, Bell, Kraaijevanger and Maisons already indicate that the method is relevant to evaluate fracture orientation and to highlight the fracture envelope.

The results presented here were obtained by PEMEX in the channelized Chicontepec reservoir complexes, which geology is typically inherited of submarine fans depositional pattern. The geology, hydrodynamics and geomechanics of reservoirs is so complex that it is a challenge to understand the reservoir response to stimulation techniques and, in general, to optimize the oil recovery and development of these channelized reservoirs.

\section{Method}

The microseismic network consisted in tubing conveyed geophones installed in the wells to be fractured. A proven technology of digital down-hole tri-axial geophone arrays is being used (E.J.M. Bathellier, and J.A.Czernichow), which provides an optimized sensitivity to low magnitude signals. The on-tubing geophone probes (Figure 2), designed for permanent applications are installed during a work-over job in the treatment well and tubing-conveyed at the reservoir level above the packer. They are strongly anchored inside the casing and are free from tubing weight and isolated from the tubing noise. Recording is achieved using a PC based multi-well event detection monitoring system.

Two neighboring wells were successively equipped, fractured and monitored. Hence, the first fracturing job was monitored from the treatment well (well B on the figures); and the second job (Figure 3 ) was monitored from both treatment and observation wells (respectively well $A$ and well $B$ ).

For both operations, the distance between the "inner tool" and the upper fracturing zone is less than 100m. And, for the second well, the distance between the "outer tool" and the upper fracturing zone is greater than $300 \mathrm{~m}$. 


\section{Data analysis and interpretation}

Despite the good network sensitivity, less than a tenth of the events were recorded by the offset well during fracturing and a hundreds of shear slip events were recorded by treatment wells during fall off. Beside these shear-slip events, acoustic emissions were also detected during shutdown. These two types of events are clearly correlated with the reservoir stimulation job, but their origin is very different. Indeed, whilst shear-slip events are related to failure mechanisms within the rock matrix in the destabilized zone around the fracture, acoustic emissions are related to hammer-pulse within the fluids filling the fracture and propagated through the fluid column.

With such a dataset, the fractures envelope can be imaged by the location of shear-slip events and the orientation of fractures can be independently estimated by the acoustic emissions polarization (Figure 4). For both wells, the computed hypocenter locations are distributed in a non symmetric cloud of seismicity (relative to the well axis) with a global trend extending no more than $195 \mathrm{~m}$ away from well bore in the $\mathrm{N} 20-30^{\circ} \mathrm{E}$ direction. Moreover, the acoustic emissions present a remarkably consistent direction (see fig.4).

\section{Conclusions}

Despite a poorly seismogeneous behaviour of the reservoir, the use of "inner microseismic monitoring surveys" allows to capture events closer to the geophones, therefore it allows to present consistent fracture orientation and to highlight an effective non symmetric behaviour of the fracture envelopes. These results would not have been collected from "outer microseismic monitoring surveys".

Microseismic monitoring results have been found helpful in achieving proper fracturing quality control and in reviewing the stimulation scheme, namely by reducing the number of fracturing levels necessary to achieve an efficient and cost effective reservoir stimulation. In addition, based on the results of this novel application in Chicontepec reservoirs, the prediction of fracture orientation along channelized reservoirs has provided a sound support in designing new development schemes. Hence locations of both well producers and water injectors have been optimized.

\section{Acknowledgments}

We would like to thank PEMEX for permission to publish this work.

\section{References}

Bell, M.R., Kraajevanger, $H$. and Maisons, C., « Integrated Downhole Monitoring of Hydraulically
Fractured Production Wells » SPE 65156 EuroPEC, Paris, 2000.

Allen, T. O. and Roberts, A. P. , Production operations, vol. 2, chapter 8 .

Wolhart, S., Berumen, S., Cipolla, C., Barton, C. and Branagan, P.: « Optimizing Low-Permeability Gas-Field Fracturing Jobs », WORLD OIL, Natural Gas: Tight Formation Stimulation section, May 2001, 70 - 80.

E.J.M. Bathellier, and J.A.Czernichow, « Permanent Downhole Seiemic Sensors for Reservoir Monitoring: A Review » OTC 8309, Houston-Texas, May 1997 


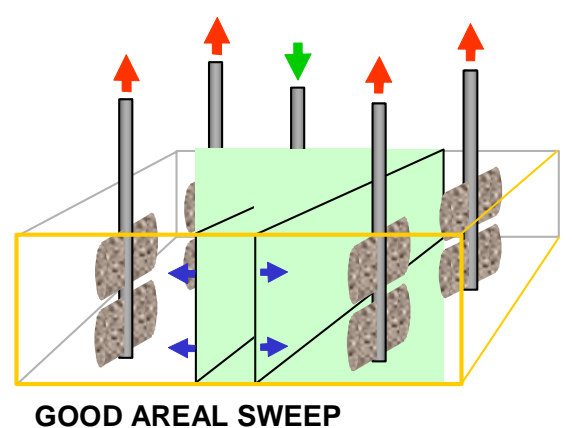

GOOD AREAL SWEEP

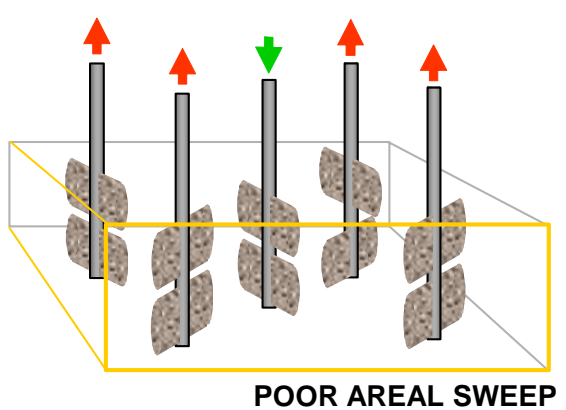

POOR AREAL SWEEP

Figure 1 - The highly conductive path generated by fracturing some distance away from the well-bore needs to be imaged in order to control the effective sweep efficiency.
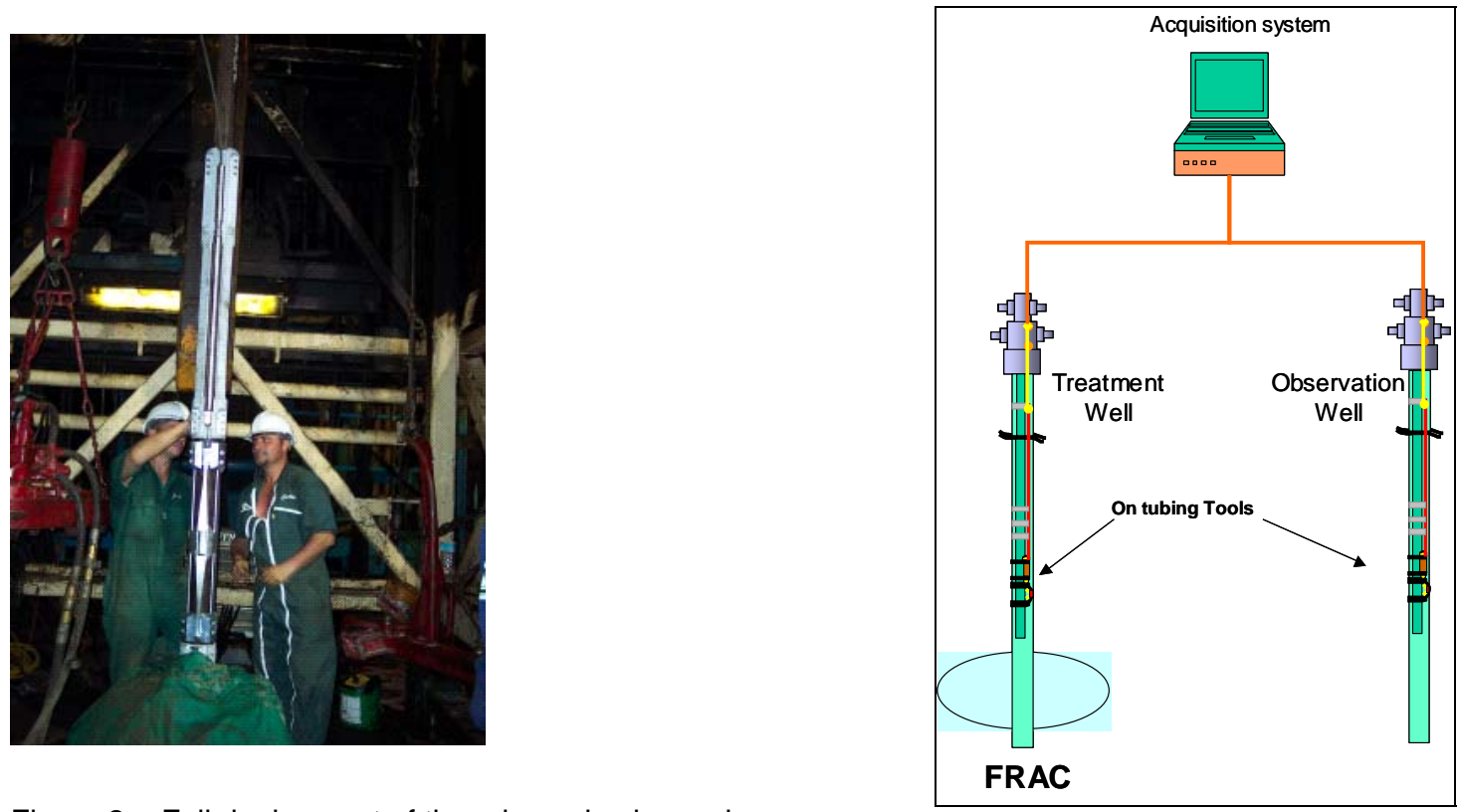

Figure 2 - Full deployment of the microseismic sonde before anchoring on the tubing. The tool, characterized by a mono-conductor telemetry, fits in the treatment well, with an identical installation as for permanent pressure gauge. The sensors assembly includes three orthogonal $28 \mathrm{~Hz}$ geophones mounted on a bow spring blade.

Figure 3 - Survey configuration for the second fracturing job. Treatment well (where the fluids are injected at very high pressures) is well $A$, observation well is well $B$. 


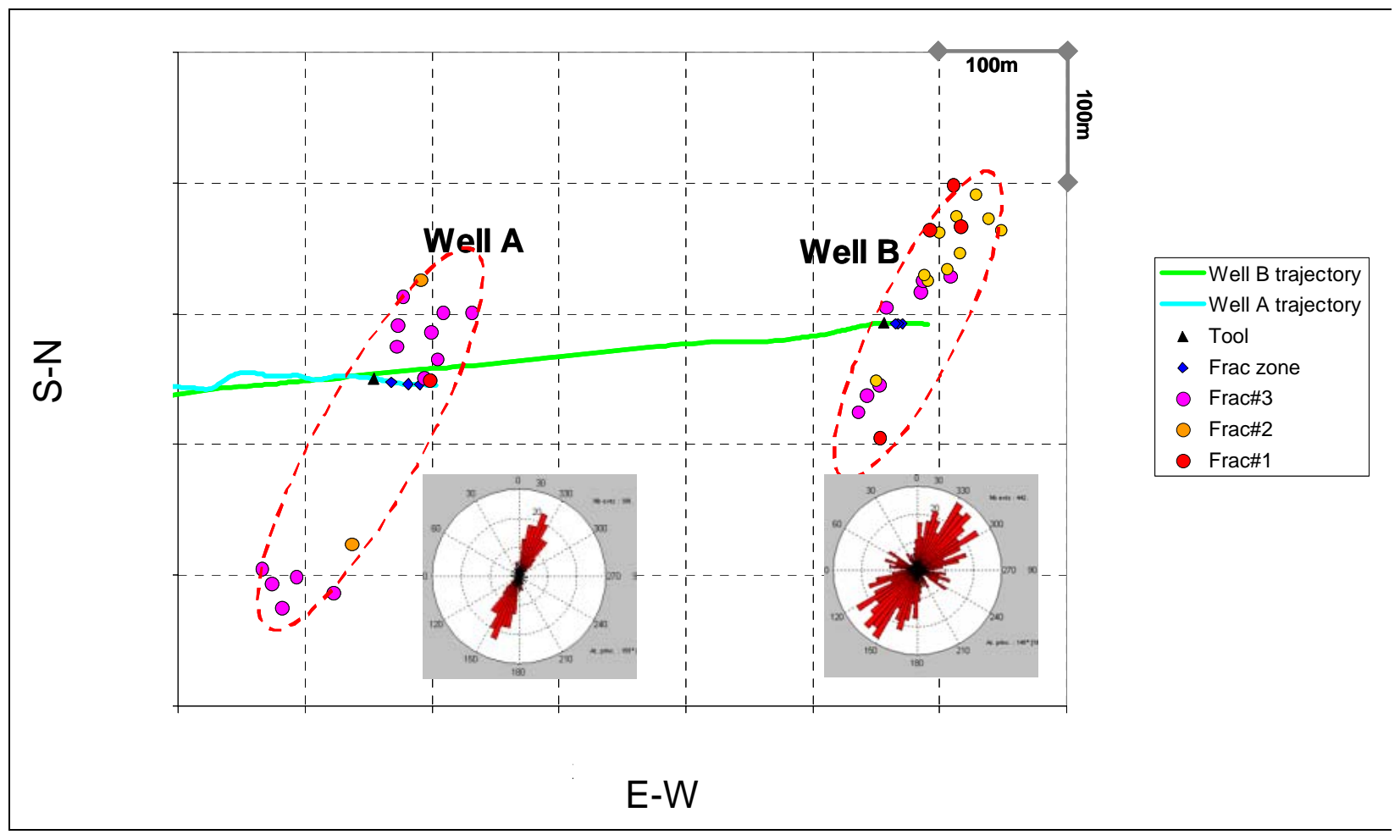

Figure 4 - Seismic events location (horizontal view) for both fracturing jobs (well $A$ and well $B$ ), and azimuth of acoustic emissions (186 and 442 events respectively). The sources distribution shows a consistent orientation (N32 ${ }^{\circ} \mathrm{E}$ for well $\mathrm{A}$ job, $\mathrm{N} 40^{\circ} \mathrm{E}$ for well $\mathrm{B}$ job) 